Fourth International Conference on Sustainable Construction Materials and Technologies http://www.claisse.info/Proceedings.htm

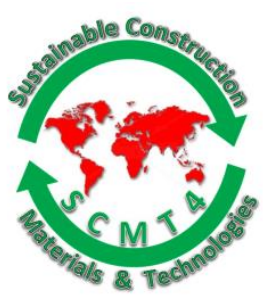

SCMT4

Las Vegas, USA, August 7-11, 2016

\title{
Characteristics of Concrete Based on Red Waste Ceramics and Reinforced by Steel Fibre
}

\author{
Jacek Katzer ${ }^{1 a}$, and Jacek Domski ${ }^{1 b}$ \\ ${ }^{1}$ Faculty of Civil Engineering Environmental and Geodetic Sciences, Koszalin University of \\ Technology, POLAND. \\ ${ }^{1 a}$ Email: < jacek.katzer@tu.koszalin.pl>, ${ }^{1 b}$ Email: <domski@wilsig.tu.koszalin.pl>
}

\begin{abstract}
Red waste ceramics is gaining increasing popularity as raw material for aggregate production. Red waste ceramic aggregate (RWCA), due to its porous nature, is characterized by very high water absorptivity. It disables utilization of traditional concrete mix designing methods. The preparation of a workable RWCA mix is quite tricky. Replacing traditional coarse aggregates by RWCA significantly influences the homogeneity of mechanical properties of cast concrete (populations of results are characterized by significantly higher standard deviation) and mechanical properties themselves, preventing its wide production and application. In the research programme these limitations were addressed through utilizing engineered hooked steel fibre and the process of internal curing. Fibres were added to the mix by volume in amounts of $0.0 \%, 0.5 \%, 1.0 \%$ and $1.5 \%$. Specimens for static tests were in a form of cubes $(150 \mathrm{~mm}$. $150 \mathrm{~mm} \cdot 150 \mathrm{~mm})$, cylinders $(\varphi=150 \mathrm{~mm}, \mathrm{~h}=300 \mathrm{~mm})$ and beams $(\mathrm{b}=150 \mathrm{~mm}, \mathrm{~h}=150 \mathrm{~mm}, 1=700$ $\mathrm{mm})$. Cubes and cylinders were used for strength tests according to EN 12390. Prismatic specimens were used for LOP test according to EN 14651:2005. Circular plates $(\varphi=1000 \mathrm{~mm}$, $\mathrm{h}=100 \mathrm{~mm}$ ) were used for testing dynamic properties of the composites. The plates were mounted on a specially tailored laboratory stand and subjected to multiple free fall impacts. During the impact tests, deflection and propagation of cracks were followed. Created fibre reinforced RWCA concrete is characterized by compressive strength reaching $52 \mathrm{MPa}$ and values of residual strengths enabling substitution of conventional reinforcement.
\end{abstract}

\section{INTRODUCTION}

Ceramic waste is the key element of the worldwide volume of construction and demolition waste [Correia et al. 2006]. One of the most promising recycling process of ceramic waste is using it as a coarse aggregate for concrete production. Research programmes focused on harnessing ceramic waste in construction industry resulted so far in successful applications of ceramic waste in concrete elements characterized by less demanding mechanical characteristics, such as pavement slabs [de Brito et al. 2005, Hendriks \& Janssen 2003]. The majority of these programmes were dealing with red waste ceramics. Using RWCA to substitute natural aggregate creates significant technological problems mainly associated with workability of a fresh mix. Red waste ceramics as porous material is characterized by very high water absorptivity. Therefore all commonly used concrete mix designing methods are not suitable for RWCA based mixes. 
RWCA concretes are usually characterized by relatively small homogeneity of main mechanical properties and limited mechanical characteristics. Currently applications of RWCA concrete are only in elements characterized by lesser mechanical performance. To overcome these performance issues one can modify RWCA concrete by an addition of steel fibre. Engineered steel fibre proved to be very effective in enhancing limited mechanical properties of concretes based on varied waste aggregates [Domski 2015, Katzer 2008, Łapko \& Grygo 2014] and thus promising achieving similar improvement in case of RWCA concrete. The RWCA particles are irregular in shape and often look like small blades rather than sphere-like grains. Size and shape characteristics of the aggregate directly influences fibre distribution and orientation [Maidl 1995, Johnston 2001]. Irregularities in aggregate particles' geometry may cause fibre agglomeration and nonuniform spacing. The key objective of the planned experimental programme was to evade major technological problems with RWCA and fibre reinforcement used simultaneously. The achieved fibre concrete due to its non-conventional properties would have multiple structural applications. Dynamically loaded structural elements, industrial floors and road pavements would be the first areas of implementation. The developed fresh mix should be characterized by good workability guaranteeing easy casting and achieving satisfactory mechanical properties of a hardened concrete. Successful merging RWCA concrete and fibre reinforcement would create new opportunities for sustainable development of construction industry.

\section{EXPERIMENTAL INVESTIGATION}

Materials. RWCA was prepared on the basis of construction debris. This raw ceramic waste consists of different types of broken and crushed ceramic elements such as: wall blocks, hollow bricks and wire-cut bricks. This kind of debris (partially contaminated by cement mortar) is very common in Europe [de Brito et al. 2005]. It emerges during the very production of elements, transportation, execution of construction etc. [Correia et al. 2006]. The creation of RWCA began with grinding the waste using an electric industrial grinder and 21 steel spheres characterized by mass varied from 1343g to 2650g [Domski et al. 2012]. The achieved all-in-aggregate was then sieved to separate fractions characterized by a diameter $32 \mathrm{~mm}<\phi<$ $1.0 \mathrm{~mm}$. The grading characteristics of RWCA including: a grading curve prepared with the help of rectangular sieve set (according to EN 933-1:2012), different fineness moduli and median diameter, are presented in figure 1. Loose bulk densities, compacted bulk density and water absorptivity by weight of RWCA (crucial for mix designing) were also tested. Results of these tests are presented in Table 1 [Cichocki et al. 2014]. Ordinary sand of post-glacial origin was used as fine aggregate. The main mineral component of this sand (washed from all-in-aggregate during hydro-classification process and thoroughly described in a previous publication [Cichocki et al. 2014]) is quartz and crystalline rock, dominated by granite. Portland cement CEM I 42.5 (EN 197-1:2011) was utilized as a binder to prepare all mixtures. Tap water (EN 1008:2002) and admixture of 1\% of type FM superplasticizer were the last ingredients of the matrix. The silica fume modified superplasticizer is characterized by density of $1.45 \mathrm{~g} / \mathrm{cm}^{3}$.

Table 1. Density and water absorptivity of used RWCA

\begin{tabular}{|c|c|c|}
\hline Loose bulk density & Compacted bulk density & Water absorptivity by weight \\
\hline$\left[\mathrm{kg} / \mathrm{m}^{3}\right]$ & {$\left[\mathrm{kg} / \mathrm{m}^{3}\right]$} & {$[\%]$} \\
\hline 948 & 1170 & 22 \\
\hline
\end{tabular}




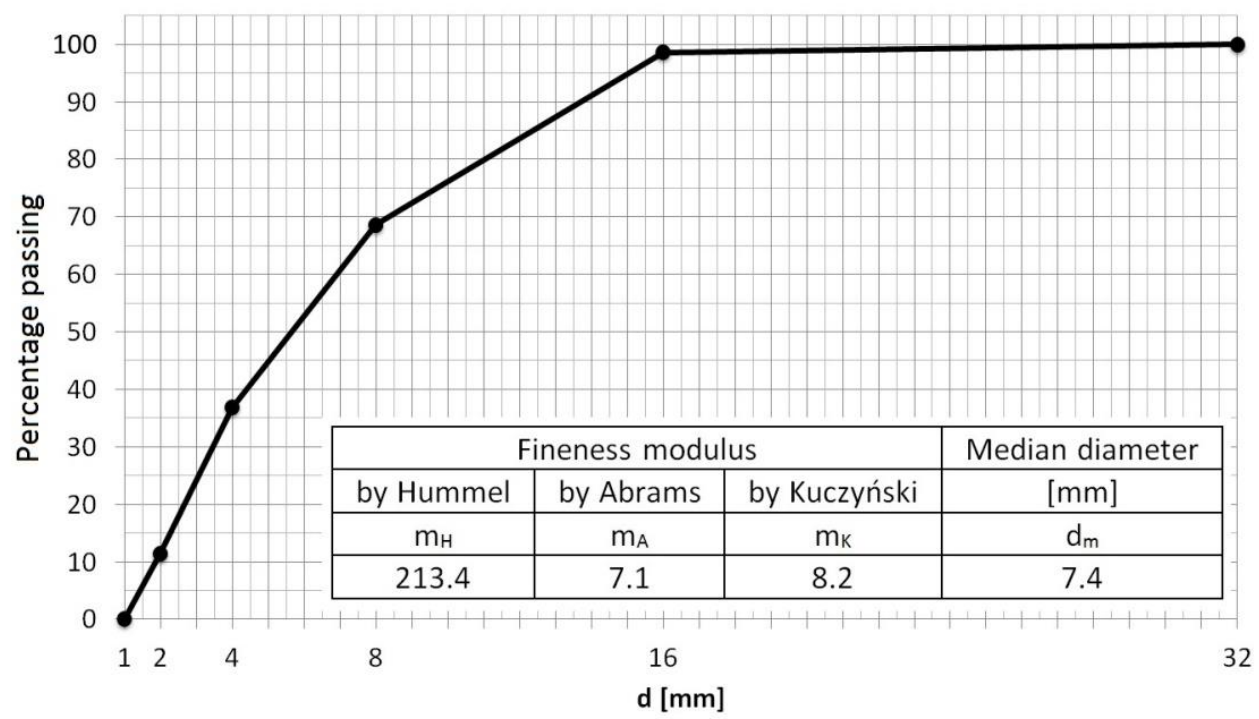

Figure 1. Grading curve and fineness moduli of used RWCA

Hooked steel fibre, as the most commonly used type of fibre in civil and structural engineering, was chosen as reinforcement. This fibre is made from cold drawn wire (steel - group I according to EN 14889-1:2006). The chosen fibre was characterized by a circular cross-section $(d=0.80 \mathrm{~mm})$ and aspect ratio $(L / d)$ of 62.5 . The main geometrical characteristics of the fibre was described with the help of fibre intrinsic efficiency ratio (FIER). FIER proposed by [Naaman 2003] has been defined as the ratio of bonded lateral surface area of fibre to its cross sectional area (see eq.1). It is a very useful parameter in case of evaluating post cracking strength of fibre concrete. The chosen fibre was characterized by FIER $=15.8$.

$F I E R=(\Psi \cdot L) / A$

where:

$\Psi$ - perimeter of the fibre, $A$ - cross sectional area of the fibre, $L$ - length of the fibre.

Apart from geometrical parameters there was also assessed mechanical characteristics of this fibre [Katzer \& Domski 2012]. Ductility of the fibre tested according to EN 14889-1:2006 was equal to 7 bends and tensile strength of the fibre $\left(R_{m}\right)$ tested according to EN 10218-1:2012 was equal to $1147 \mathrm{MPa}$.

Mixture proportions. Due to the fact that RWCA was characterized by significant absorptivity (see Table 1) it was impossible to utilize ordinary techniques of concrete mix preparation. RWCA had to be fully saturated before the use. The RWCA saturation resulted in stable and uniform properties of the fresh concrete mixes during all stages of handling, mixing and casting. Calculated mix composition based on dry aggregates had to be adjusted to take into account water absorbed by RWCA. This water influences both the consistency of a fresh mix and the curing process ("autogenous curing", also known as "internal wet curing" [Suzuki et al. 2009]). The reduction of added tap water had to be conducted using a traditional "trial and error method" because the proportions of water influencing consistency and curing are unknown. The mix proportions of cast composites were as follows: saturated RWCA - 830kg (the amount of trapped water $-182.6 \mathrm{~kg}$ ), sand $-652 \mathrm{~kg}$, cement $-307 \mathrm{~kg}$, tap water $-92 \mathrm{~kg}$, superplasticizer $-3.1 \mathrm{~kg}$. The total mass of all ingredients for casting one cubic meter of RWCA concrete was equal to $1884.1 \mathrm{~kg}$. The mixes were reinforced by fibre addition in volumes of $0.0 \%, 0.5 \%, 1.0 \%$ and $1.5 \%$. Cast specimens were compacted in two layers using a vibrating table. For the initial 24 hours specimens were kept in moulds covered with 
polyethylene sheets. Subsequently specimens were demoulded and placed in a water tank (temp: $+21^{\circ} \mathrm{C} \pm$ $\left.1^{\circ} \mathrm{C}\right)$. Afterwards the specimens were kept in a water tank. All together curing lasted 28 days.

Conducted testes. The consistency of all fresh mixes was tested using a degree of compactability method (EN 12350-4:2009). Cube and cylinder specimens were used for traditional strength tests (compressive and splitting tensile) and establishing static modulus of elasticity. Beams were utilized to get flexural characteristics of tested RWCA concretes including all residual strengths. Circular plates were subjected to impact tests on the tailored lab stand. The stand with three massive supports is presented in figure 2 [Cichocki et al. 2014]. The impact test comprised of free fall of 40kg mass from the height of $1.0 \mathrm{~m}$. After each impact the deflection of the plate and cracks width were measured. Deflection was measured in 17 locations and cracks width was measured on the bottom surface of a slab in three distances $(10 \mathrm{~cm}, 20 \mathrm{~cm}$ and $30 \mathrm{~cm}$ ) from the centre of a slab. Density checks were conducted on all available specimens. The prepared specimens and conducted test programme are summarized in Table 2.

Table 2. Specimens and conducted tests

\begin{tabular}{|c|c|c|c|}
\hline \multicolumn{2}{|c|}{ Specimens } & \multicolumn{2}{c|}{ Tests } \\
\hline Shape & Size $[\mathrm{mm}]$ & Property & Code \\
\hline Fresh mix & - & consistency & EN 206:2013 \\
\hline Cube & $b=150, h=150, l=150$ & $\begin{array}{c}\text { compressive strength } \\
\text { splitting tensile strength }\end{array}$ & $\begin{array}{c}\text { EN 12390-3:2009 } \\
\text { EN 12390-6:2009 }\end{array}$ \\
\hline Cylinder & $\varphi=150, h=300$ & $\begin{array}{c}\text { compressive strength } \\
\text { static modulus of elasticity }\end{array}$ & $\begin{array}{c}\text { EN 12390-3:2009 } \\
\text { EN 12390-13:2013 }\end{array}$ \\
\hline Beam & $b=150, h=150, l=700$ & $\begin{array}{c}\text { flexural tensile strength } \\
\text { shear strength }\end{array}$ & $\begin{array}{c}\text { EN 14651:2005 } \\
\text { JCI-SF6:1984 }\end{array}$ \\
\hline Circular plate & $\varphi=1000, h=100$ & impact tests & tailored lab stand \\
\hline
\end{tabular}
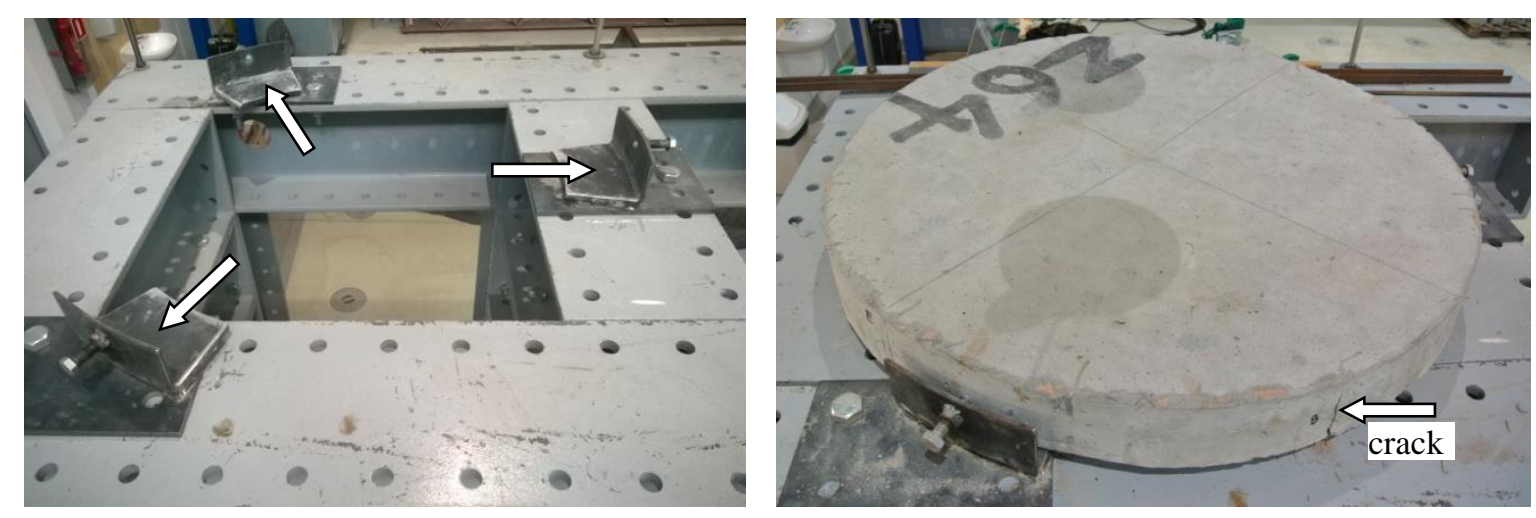

Figure 2. Three supports of the tailored lab stand for impact tests and a slab during the test

Flexural tensile strength test according to EN 14651:2005, is conducted on a notched beam. It enables calculation of strength at a limit of proportionality $\left(f_{L O P}\right)$ and four different values of residual strength $f_{R l}$, $f_{R 2}, f_{R 3}, f_{R 4}$ [Di Prisco et al. 2009] which are associated with specific values of the Crack Mouth Opening Displacement (CMOD) of the notch. The crucial values of CMOD are equal to $0.5 \mathrm{~mm}, 1.5 \mathrm{~mm}, 2.5 \mathrm{~mm}$ and $3.5 \mathrm{~mm}$. It is commonly assumed that the most important residual strengths are $f_{R I}$ and $f_{R 3}$ which can be used for a limit state design. For any given fibre reinforced concrete, $f_{R I}$ characterizes the serviceability limit state (SLS) and $f_{R 3}$ characterizes the ultimate limit state (ULS). According to fib Model Code [Model Code 2010] the toughness of fibre reinforced concrete can be assessed using two parameters: $f_{R I}$ and $f_{R 3} / f_{R I}$. The 
first residual strength represents the strength class (10 classes available from 1.0MPa to 8.0MPa). The ratio of $f_{R 3} / f_{R I}$ represents the most common cases of softening/hardening of fibre reinforced concrete (4 classes available: "a", "b", "c" and "d"). fib Model Code [Model Code 2010] also defines conditions to be fulfilled to enable traditional reinforcement substitution: $f_{R 3} / f_{R I}>0.5$ and $f_{R I} / f_{L O P}>0.4$.

\section{RESULTS AND DISCUSSION}

In case of fibre reinforced concretes it is very important to achieve consistency allowing utilization of ordinary casting and compacting techniques. All prepared mixes were characterized by consistency class C2 (EN 206:2013), thus there were no doubts considering quality of casting and compaction of RWCA fibre reinforced concrete.

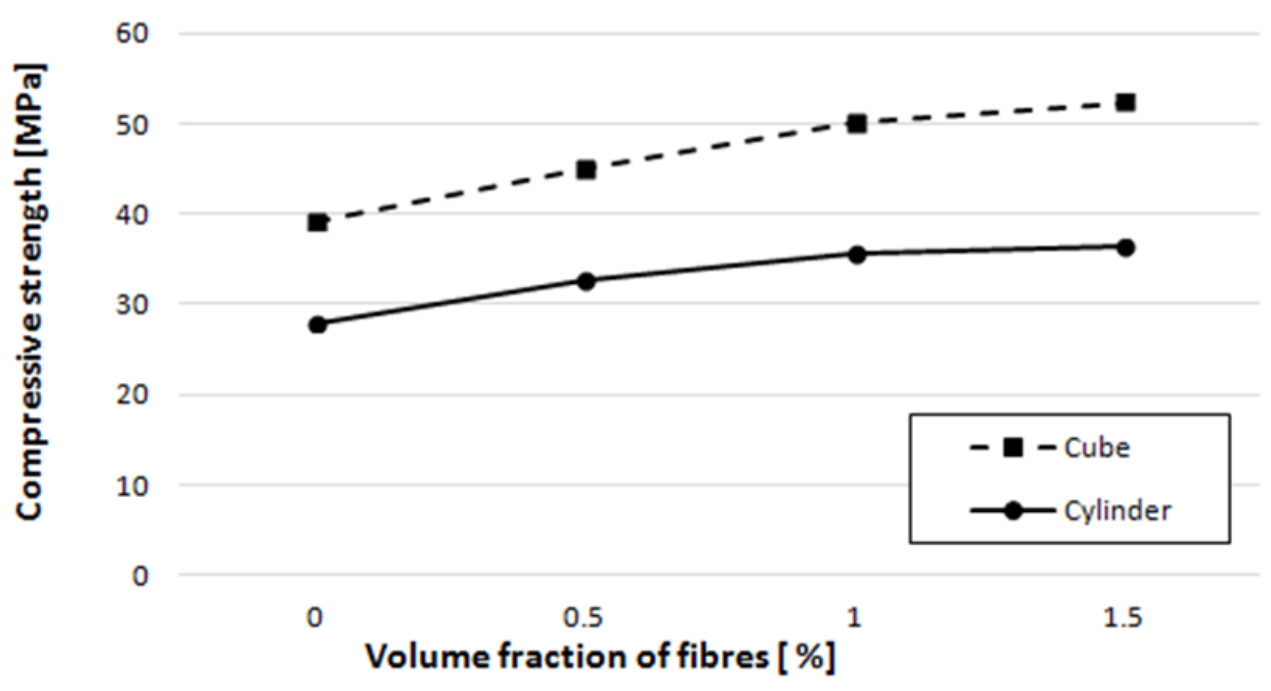

Figure 3. Compressive strength tested on cube and cylinder specimens

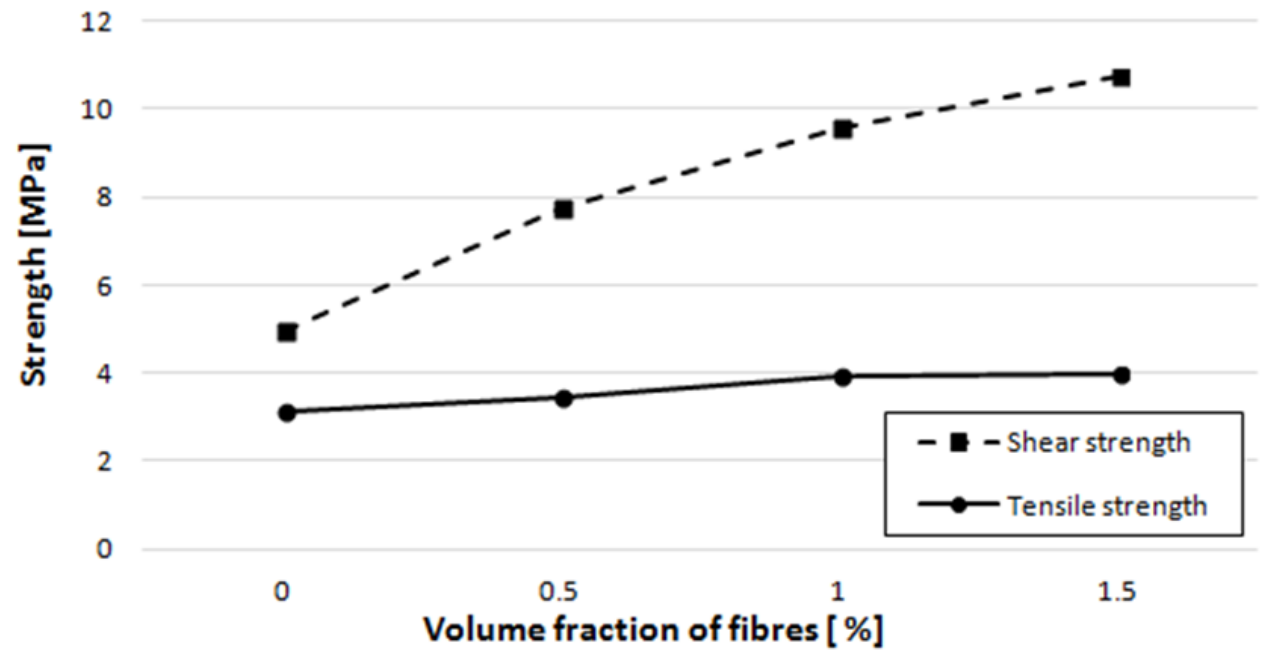

Figure 4. Shear and tensile strength 
Table 3. Residual strengths and strength class of tested composites

\begin{tabular}{|l|c|c|c|c|}
\hline \multicolumn{1}{|c|}{ Property } & Unit & \multicolumn{3}{c|}{ Value } \\
\hline$V_{f}$ & {$[\%]$} & 0.5 & 1.0 & 1.5 \\
\hline$f_{L O P}$ (limit of proportionality according to EN 14651) & {$[\mathrm{MPa}]$} & 3.2 & 2.9 & 2.7 \\
\hline$f_{R 1}$ (residual flexural strength corresponding with $\left.C M O D_{1}\right)$ & {$[\mathrm{MPa}]$} & 3.9 & 4.7 & 7.1 \\
\hline$f_{R 2} \quad$ (residual flexural strength corresponding with $\left.C M O D_{2}\right)$ & {$[\mathrm{MPa}]$} & 3.8 & 5.0 & 8.5 \\
\hline$f_{R 3}$ (residual flexural strength corresponding with $\left.C M O D_{3}\right)$ & {$[\mathrm{MPa}]$} & 3.6 & 4.8 & 8.5 \\
\hline$f_{R 4} \quad$ (residual flexural strength corresponding with $\left.C M O D_{4}\right)$ & {$[\mathrm{MPa}]$} & 3.6 & 4.6 & 8.2 \\
\hline$f_{R 3} / f_{R 1} \quad(>0.5)$ & {$[-]$} & 0.92 & 1.03 & 1.19 \\
\hline$f_{R 1} / f_{L O P}(>0.4)$ & {$[-]$} & 1.2 & 1.6 & 2.6 \\
\hline Conventional reinforcement substitution & {$[-]$} & enabled & enabled & enabled \\
\hline Strength class according to fib Model Code 2010 & {$[-]$} & $3 \mathrm{c}$ & $4 \mathrm{c}$ & $7 \mathrm{~d}$ \\
\hline
\end{tabular}

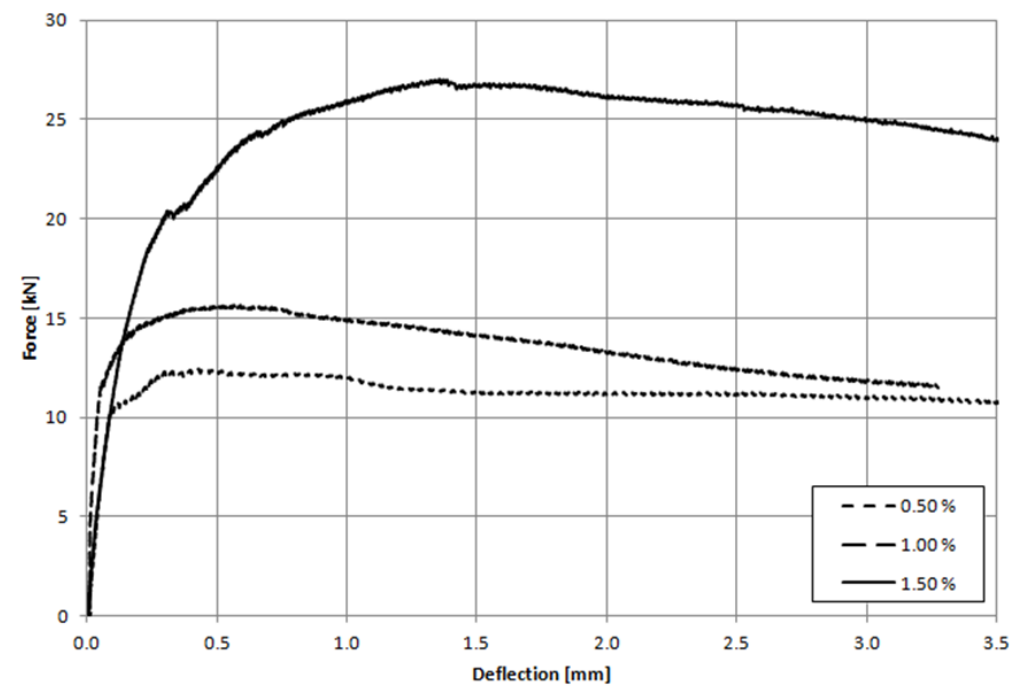

Figure 5. Flexural characteristics of tested composites

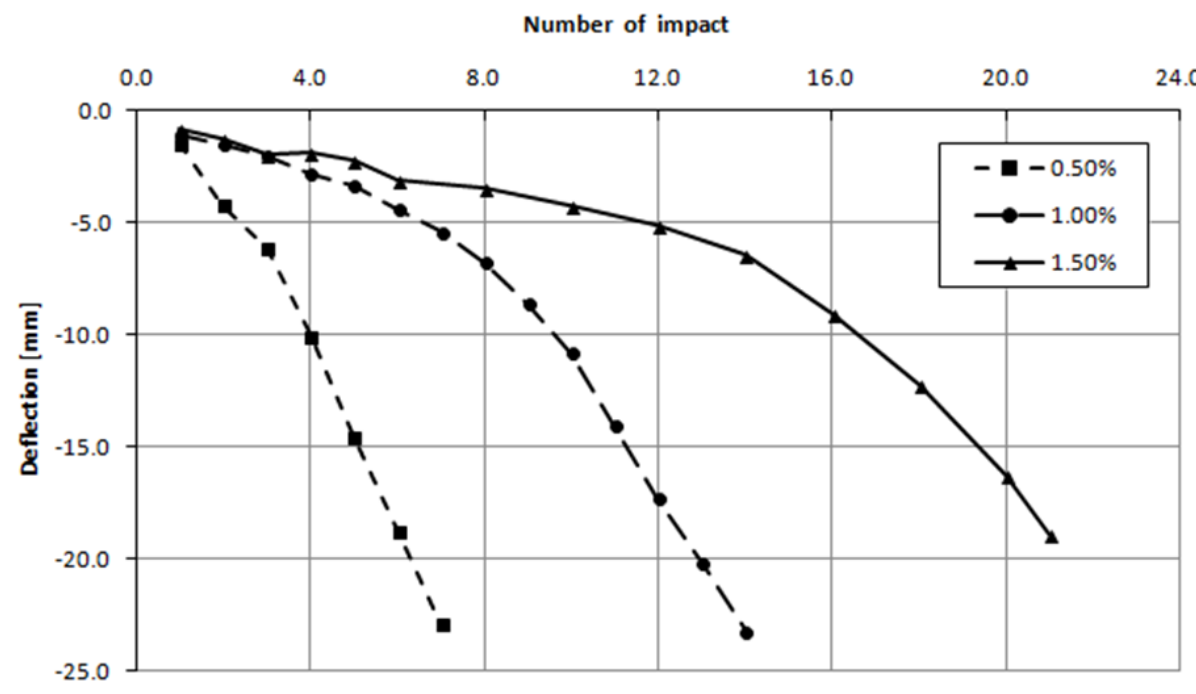

Figure 6. Deflection of tested slabs after varied number of impacts 


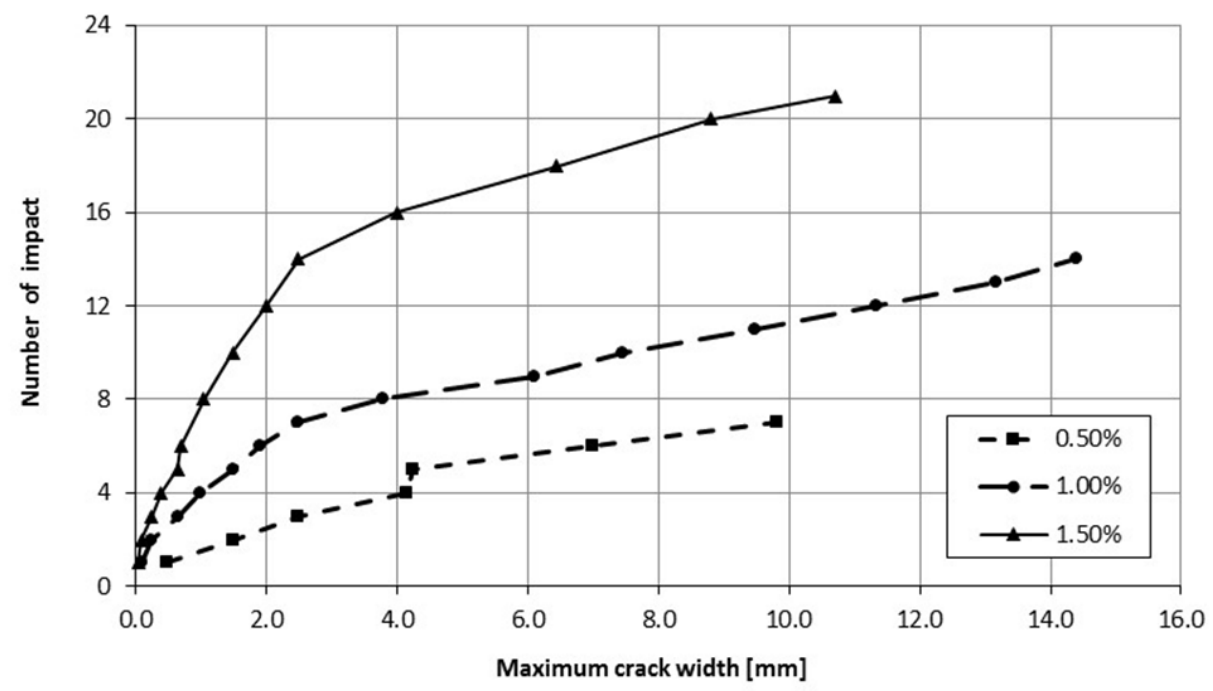

Figure 7. Maximum crack opening after varied number of impacts

RWCA concrete with no reinforcement is characterized by density of $2001 \mathrm{~kg} / \mathrm{m}^{3}$. With the increase of fibre addition the density of the RWCA concretes is getting larger and larger. The concrete reinforced by $1.5 \%$ of fibre (maximum volume) reaches the density of $2080 \mathrm{~kg} / \mathrm{m}^{3}$. Static modulus of elasticity varied from 22 GPa to $24 \mathrm{GPa}$ for unreinforced and reinforced by $1.5 \%$ of fibre RWCA concrete respectively. Strength characteristics of tested RWCA concretes are presented in figure 3, 4 and 5. Compressive strength, shear strength and tensile strength are growing along the increasing volume of added fibre. Unreinforced RWCA concrete is characterized by "cube" compressive strength of 39.1MPa and "cylinder" compressive strength of $27.9 \mathrm{MPa}$. Concrete reinforced by $V_{f}=1.5 \%$ is characterized by "cube" compressive strength of 52.3MPa and "cylinder" compressive strength of $36.3 \mathrm{MPa}$ (see figure 3 ). In both cases strength of RWCA concrete reinforced by $V_{f}=1.5 \%$ is over $30 \%$ higher than the strength of the unreinforced one. The differences between "cylinder" and "cube" compressive strengths of RWCA concretes are higher than those described by EN 206 for ordinary concrete. The unreinforced RWCA concrete fulfils requirements for class C25/30 (theoretical strength difference 5.0MPa) and the RWCA modified by maximum volume of fibre fulfils requirements for $\mathrm{C} 35 / 45$ (theoretical strength difference 10.0MPa). In assigning both strength classes the value of "cylinder" strength was critical and thus "cube" strength was underestimated. The difference in cube-cylinder strength for unreinforced RWCA concrete and RWCA concrete with $1.5 \%$ of fibre is equal to $11.2 \mathrm{MPa}$ and $16.0 \mathrm{MPa}$ respectively. Therefore the strength classes dedicated for ordinary concrete are subjected to large inaccuracy in case of RWCA fibre reinforced concrete.

Shear strength of tested concretes is presented in figure 4. It ranges from 5.0MPa for unreinforced concrete to $10.9 \mathrm{MPa}$ for the concrete reinforced by maximum fibre volume (improvement of $118 \%$ ). The tensile performance of RWCA concrete is improved only by $29 \%$ by fibre addition. Tensile strength values are from 3.1MPa for unreinforced concrete to $4.0 \mathrm{MPa}$ in case of concrete reinforced by maximum fibre volume (see figure 4).

Flexural tensile characteristics in a form of force-deflection relationship of tested concretes are presented in figure 5. These characteristics were used to calculate LOP strength and all four residual strengths. The highest value of $f_{L O P}$ was achieved by composite reinforced by $0.5 \%$ of fibre. For increasing volume of added fibre the value of $f_{L O P}$ was getting smaller and smaller. The overall fall of $f_{L O P}$ value was equal to $15.6 \%$. The values of $f_{R, I}$ ranged from $3.9 \mathrm{MPa}\left(V_{f}=0.5 \%\right)$ to $7.1 \mathrm{MPa}\left(V_{f}=1.5 \%\right)$ giving an improvement of $182 \%$. In case of $f_{R, 3}$ the adequate strength improvement was even more significant (from 3.6MPa for $V_{f}$ $=0.5 \%$ to $8.5 \mathrm{MPa}$ for $V_{f}=1.5 \%$ ) and equal to $236 \%$. The achieved values of residual strengths $f_{\mathrm{R}, 1}$ and $f_{\mathrm{R}, 4}$ 
of all tested RWCA fibre reinforced concretes are significantly larger than the required minimum. There were computed values of two factors: $f_{\mathrm{R}, 3} / f_{\mathrm{R}, 1}>0.5$ and $f_{\mathrm{R}, 1} / f_{\mathrm{LOP}}>0.4$ for all tested concretes. All residual strengths, assigned strength classes (according to Model Code 2010) and enabled conventional reinforcement substitution are presented in Table 3. Two of tested composites $\left(V_{f}=0.5 \%\right.$ and $\left.1.0 \%\right)$ are characterized by strength class "c" and one $\left(V_{f}=1.5 \%\right)$ by strength class "d". Class "c" means that the composites represent slightly hardening characteristics. Class " $\mathrm{d}$ " means that the composite represents significantly hardening characteristics. Combining these features with big differences in values of $f_{\mathrm{R}, 1}$ leads to the conclusion that only composite reinforced by $1.5 \%$ of fibre reached full efficiency of fibre/matrix interaction.

The results of the slab impact test are presented in figure 6 and Table 4. Reinforced slabs were considered as destroyed when deflection $(\delta)$ was reaching $20 \mathrm{~mm}$. After 6 impacts all tested slabs were characterized by $\delta \leq 20 \mathrm{~mm}$ (the brittle unreinforced slab was ultimately destroyed after the first impact). Crack mouth openings are much wider than the limit of $0.4 \mathrm{~mm}$ defined by EN 1992-1-1:2004 (see figure 7). One has to keep in mind that in case of dynamic loadings serviceability limits are of secondary interest.

Table 4. Results of the slab impact tests

\begin{tabular}{|c|c|c|c|c|}
\hline $\begin{array}{c}V_{f} \\
{[\%]}\end{array}$ & $\begin{array}{c}\delta \text {-after 6 impacts } \\
{[\mathrm{mm}]}\end{array}$ & $\begin{array}{c}\text { Failure } \\
\text { after № of impacts }\end{array}$ & $\begin{array}{c}\delta>0.4 \mathrm{~mm} \\
\text { after № of impacts }\end{array}$ & $\begin{array}{c}\delta_{\text {MAX }} \\
{[\mathrm{mm}]}\end{array}$ \\
\hline 0.5 & 18.7 & 7 & 1 & 22.9 \\
\hline 1.0 & 4.4 & 14 & 3 & 23.2 \\
\hline 1.5 & 3.0 & 21 & 5 & 18.9 \\
\hline
\end{tabular}

\section{CONCLUSION}

Using strength class of ordinary concrete to describe RWCA fibre reinforced concretes gives misleading information. Mechanical properties of RWCA steel fibre reinforced concretes allowed to classify them as $3 \mathrm{c}, 4 \mathrm{c}$ and $7 \mathrm{~d}$. Tested RWCA fibre reinforced concretes are characterized by mechanical properties enabling substitution of conventional reinforcement. Deflections of slabs (after equal energy input of 6 impacts) are in proportion of 1:1.5:6.0 for composites reinforced by $0.5 \%, 1.0 \%$ and $1.5 \%$ of fibre respectively.

\section{REFERENCES}

Cichocki, K., et al., (2014). "Impact resistant concrete elements with nonconventional reinforcement." Rocznik Ochrona Środowiska, 16 (part 2), 1-99.

Correia, J.R., et al., (2006). "Effects on concrete durability of using recycled ceramic aggregates." Materials and Structures. 39, 169-177.

De Brito, J., et al., (2005). "Mechanical behaviour of non-structural concrete made with recycled ceramic aggregates." Cement and Concrete Composites, 27, 429-433.

Di Prisco, M., et al., (2009). "Fibre reinforced concrete: new design perspectives." Materials and Structures. 42:1261-1281.

Domski, J., (2015). "Long-term study on fibre reinforced fine aggregate concrete beams based on waste sand." Rocznik Ochrona Środowiska, 17, 188-199.

Domski, J., et al., (2012). "Load-CMOD Characteristics of Fibre Reinforced Cementitious Composites Based on Waste Ceramic Aggregate.” Rocznik Ochrona Srodowiska, 14, 69-80. 
EN 197-1:2011. "Cement. Composition, specifications and conformity criteria for common cements", 38 pages.

EN 206:2013. "Concrete. Specification, performance, production and conformity”, 95 pages.

EN 933-1:2012. "Tests for geometrical properties of aggregates. Determination of particle size distribution. Sieving method", 18 pages.

EN 1008:2002. "Mixing water for concrete. Specification for sampling, testing and assessing the suitability of water, including water recovered from processes in the concrete industry, as mixing water for concrete", 19 pages.

EN 1992-1-1:2004. "Design of concrete structures. General rules and rules for buildings", 209 pages.

EN 10218-1:2012. "Steel wire and wire products. General. Test methods", 12 pages.

EN 12350-4:2009. "Testing fresh concrete. Degree of compactability”, 10 pages.

EN 12390-3:2009. "Testing hardened concrete. Compressive strength of test specimens", 20 pages.

EN 12390-6:2009. "Testing hardened concrete. Tensile splitting strength of test specimen”, 13 pages.

EN 12390-13:2013. "Testing hardened concrete. Determination of secant modulus of elasticity in compression", 16 pages.

EN 14651:2005. "Test method for metallic fibered concrete - Measuring the flexural strength (limit of proportionality (LOP), residual)", 17 pages.

EN 14889-1:2006. "Fibres for concrete. Steel fibres. Definitions, specifications and conformity”, 25 pages.

Hendriks, C.F., and Janssen, G.M.T., (2003). "Use of recycled materials in construction." Materials and Structures, 36, 604-608.

JCI-SF6:1984 "Method of test for shear strength of fibre reinforced concrete", 3 pages.

Johnston, C.D., (2001). "Fibre reinforced cements and concretes." Gordon and Breach Science Publishers, Amsterdam.

Katzer, J., (2008). "Properties of Precast SFRCC Beams Under Harmonic Load. Science and Engineering of Composite Materials.", 15 (2), 107-120.

Katzer, J., and Domski, J., (2012). "Quality and mechanical properties of engineered steel fibre used as reinforcement for concrete." Construction and Building Materials, 36, 243-248.

Łapko, A., and Grygo, R., (2014). "Effectiveness of the use of recycling aggregate concrete for sustainable building structures." Rocznik Ochrona Środowiska, 16, 627-638.

Maidl, B.R., (1995). "Steel fibre reinforced concrete.” Ernst \& Sohn, Berlin.

Model Code 2010. (2010). "First complete draft. International Federation tor Structural Concrete (fib)", Bulletin 55, pages.

Naaman, A.E., (2003). "Engineered Steel Fibres with Optimal Properties for Reinforcement of Cement Composites." Journal of Advanced Concrete Technology, 1, 241-252.

Suzuki, M., et al., (2009). "Use of porous ceramic waste aggregates for internal curing of high-performance concrete." Cement and Concrete Research, 39, 373-381. 